\section{Dramaturgos e editores}

\author{
Alberto Guzik
}

Falar do livro Leone äe'Sommi - um judeu no teatro da Renascença italiana requer, obrigatoriamente, que antes se examine, mesmo rapidamente, a figura de seu editor, J. Guinsburg. Coração e alma da Editora Perspectiva, Guinsburg vem revelando, ao longo do quarto de século de existência da casa, uma curiosa e hoje rara atitude. Não lhe interessam os best-sellers, mas os livros capazes de estimular o diálogo, de contribuir para o enriquecimento intelectual do leitor. Nenhuma obra sai com a chancela da Perspectiva sem passar pelo rigoroso crivo de seu proprietário. E esse demonstra o interesse multifacetado de um renascentista.

Acolhe lado a lado textos sobre física e literatura, antropologia e matemática, artes plásticas e psicologia, música popular e semiologia, etc., etc. E evita escritos de divulgação, de iniciação, preferindo trabalhos fundamentais em cada área. Para um pequeno exemplo dessa política, basta lembrar que a Perspectiva foi a primeira a lançar no Brasil, ainda em meados dos anos 60, os ensaios axiais de Umberto Eco, A obra aberta e Apocaltpticos e integrados.

Professor titular da Universidade de São Paulo, J. Guinsburg tem desempenhado no magistério papel igualmente importante. Através de sua visão rigorosa e abrangente, mostrou a sucessivas turmas que teatro não é apenas ação, mas também reflexão. Atuando de início no curso de crítica da Escola de Arte Dramática e mais tarde no Departamento de Teatro da ECA, Guinsburg revelou-se como professor severo e fascinante.

Seus vôos pela estética da cena, dos gregos clássicos aos contemporâneos, nunca se limitam à rotineira análise histórica e didática. Vão além, tornam vivo o momento para iluminar opções indestrinçáveis do contexto em que nasceram. E ele exige do aluno uma vivência real do autor em estudo, seja Aristóteles, Hegel ou Artaud. Não aceita a ruminação decorada. Requer que a percepção pessoal de cada estudante seja posta em ação para o entendimento do processo cultural.

Leone de'Sommi, lançado em 1989, permitiu a J. Guinsburg a união de duas grandes paixōes intelectuais: a cultura judaica e o teatro. A ambos tem dado o melhor de seu tempo e de seus esforços. Ao judaísmo dedicou toda uma coleção da Perspectiva, justamente a Judaica, onde editou de textos sacros a obras laicas, de escritores bíblicos a contistas contemporâneos. É talvez o único painel de tal abrangência existente em língua portuguesa. O teatro está disseminado em todas as demais coleções da editora, Estudos, Debates, Kronos e Textos. São na maioria ensaios sobre a atividade teatral, que incluem clássicos do gênero, como A tragédia grega, de Albin Leski. Mas o maior número de livros teatrais da Perspectiva é de brasileiros contemporâneos, preocupados em mapear um ou mais aspectos da cultura cênica tupiniquim.

Tomando conhecimento da obra de de'Sommi, Guinsburg passou a traduzi-la, certamente pensando numa edição. Dedicou-se primeiro a Quatro diálogos em matéria de representação cênica, escritos originalmente em italiano, e depois à Comédia do ma-

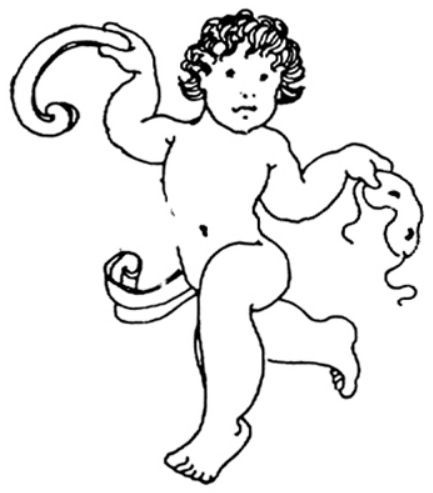

ALBERTO GUZIK é crftico de teatro do Jornal da Tarde e autor de TBC: crónica de um sonho (Editora Perspectiva).

Leone de'Sommi: um judeu no teatro da Renascença italiana, traduçăo de Jacơ Guinsburg. Săo Paulo, Editora

Perspectiva, 246 pp.

\section{Junho


trimônio, redigida em hebraico e considerada por historiadores como a primeira obra teatral composta nessa língua. Para apresentar os Diálogos, que unem prática e teoria teatral, e a Comédia, peça caracteristicamente renascentista, de ótima qualidade, J. Guinsburg escreveu alentado ensaio, que ocupa 50 das 250 páginas do livro.

$\mathrm{O}$ texto introdutório, que atende pelo mesmo título do livro, é um escrito típico de J. Guinsburg. Objetivo, preciso, tem estilo claro, que não cede às tentações da moda, a floreios inúteis de linguagem. $\mathrm{O}$ autor não deseja ser admirado por seu brilho intelectual (que é inegável) nem pelo rigor de seu estilo (cristalinamente óbvio). Deseja chamar a atenção para o objeto estudado, transmitindo ao leitor todo o seu entusiasmo, seu fascŕnio por uma personagem ímpar. A mesma atitude será encontrada em qualquer texto saído da pena de J. Guinsburg. Essa modéstia que remete para o objeto estudado, não para o estudioso, característica de qualquer scholar que se preze, é encontrável nos ensaios de Guinsburg desde os anos 50, quando ele contribuía com alentados artigos para o "Suplemento Cultural" de $O$ Estado de S. Paulo.

Desde então, em dezenas de estudos, ensaios, artigos introdutórios a antologias, publicados em jornais, revistas e suplementos do Brasil e do exterior, o crítico tem contribuído para a cultura e para o teatro com análises precisas, sucintas. $O$ fato de o ensaísta quase sempre ocultar-se por trás dos fatos e dados que examina não impede, porém, que o leitor apreenda sua inteligência aguda, sua notável erudição. Nem o humour e a fina ironia com que trespassa seus assuntos, iluminando freqüentemente ângulos ins 6 litos.

Se alguma coisa temos a reclamar da atividade do ensaísta J. Guinsburg é que seus escritos têm gerado livros com menos assiduidade do que seria desejável. Stanislávski e $o$ Teatro de Arte de Moscou (Perspectiva, 1985), obra crítico-histórica sobre o velho

\section{Se alguma coisa temos a}

reclamar da atividade do

ensaísta Jacó Guinsburg,

é de que seus escritos

têm gerado livros com

menos assiduidade do que

seria desejável.

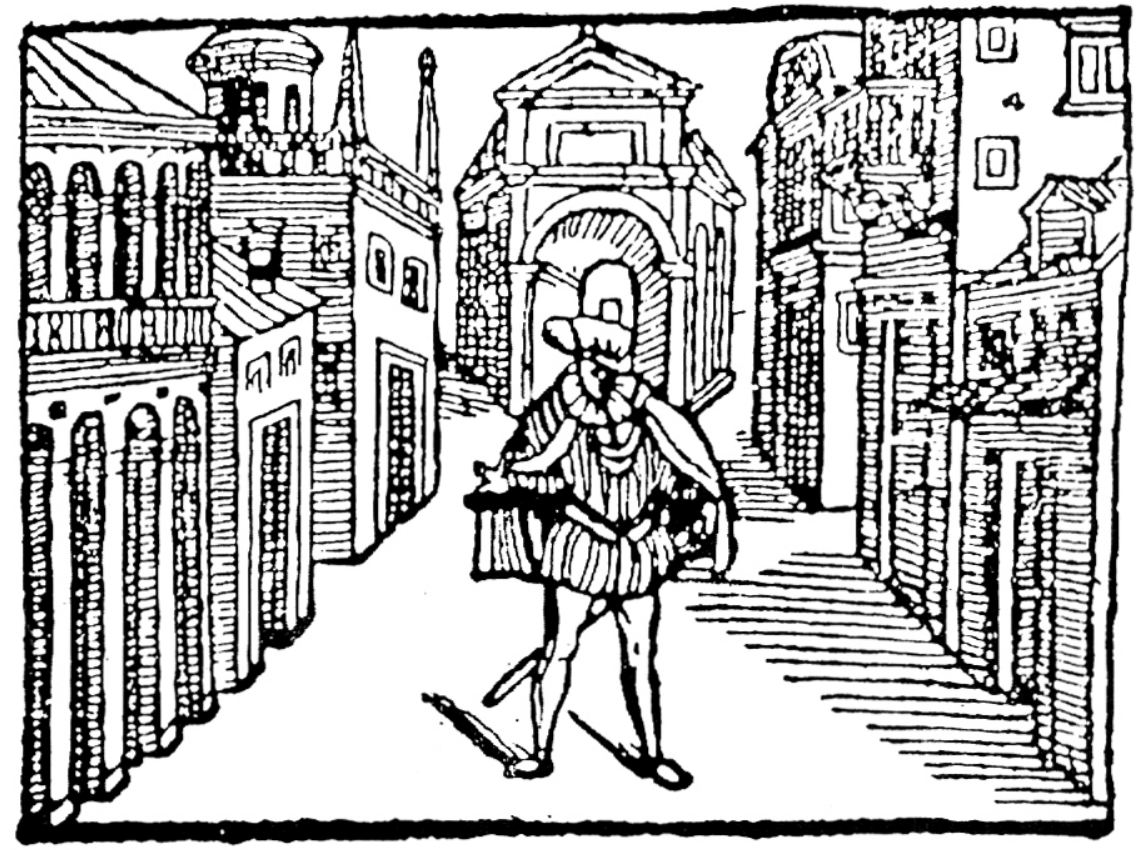
mestre russo, mostra o quanto perdemos por não ter mais exemplares dessa agudez de análise em edições acessíveis. $O$ calibre intelectual de Guinsburg não é inferior ao de seu grande amigo, o saudoso e modelar Anatol Rosenfeld. Para as presentes e futuras gerações de estudantes de teatro, é imperioso que a fragmentada produção de Guinsburg seja editada. Sua lucidez é tão importante quanto sua abrangência. E o ensaísta abarca da tragédia grega ao teatro judeu, da estética do Barroco à do Romantismo, da revolução na interpretação de Stanislávski à surpreendente modernidade do renascentista Leone de'Sommi.

O que nos traz de volta a Um judeu no teatro da Renascença italiana. A figura de de'Sommi, cujos traços biográficos são apresentados de forma sucinta mas precisa no ensaio introdutório do livro, poderia ser considerada como a de um renascentista típico, não fosse ele de estirpe judaica. Nasceu em Mântua, no século XVI, quando a cidade era, sob o domínio e mecenato dos Gonzagas, um próspero centro comercial e artístico. Iehuda Leone ben Itzhak Sommo, ou Leone de Sommo de Portaleone ou Leone Ebreo de Sommi viveu de 1525 ou 1527 a 1586 ou 1592 .

"Dramaturgo, encenador, teórico do teatro, poeta... participou intensamente da vida teatral renascentista com numerosas criações dramáticas e cênicas e com concepções teatrais cuja originalidade vem sendo destacada crescentemente pelos estudos críticos modernos." Assim J. Guinsburg nos apresenta a personagem. A descrição nada teria de excepcional se não se referis-

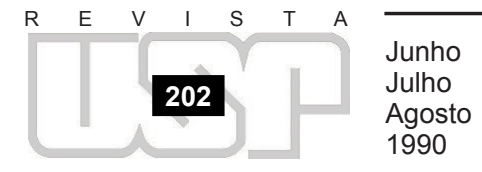


se a um filho do Povo do Livro, que tradicionalmente não encorajou (até pelo contrário) as artes cênicas. Em Leone de'Sommi o leitor encontra já vivenciado um dilema que seria o de muitos judeus na modernidade, o do duplo vínculo. De um lado, a tradição secular de uma religião exigente e exclusivista, de outro, a cultura do país de adoção, uma língua outra que não a familiar, outros modos de expressão.

Segundo as informações dadas pelo autor da introdução, percebemos que o teatrólogo italiano não escapou aos problemas acarretados pelo duplo vínculo. Sua atuação em áreas laicas, como a literatura e o teatro, valeu-lhe ter sido alvo de referências pouco elogiosas em obra de certo Rabi Iaakov Fano. De qualquer forma, de'Sommi não foi o único judeu a conseguir integrar-se no teatro da Renascença italiana. E de algum modo soube equilibrar o que a corte mantuana e o grupo de correligionários exigiam dele. Quando morreu, foi elogiado por esses e por aqueles.

O teatro italiano da Renascença foi um prisioneiro da tradição erudita e cortesã. Não soube incorporar, em sua tentativa de ressurreição dos modelos teatrais da Grécia clássica, as fontes populares, que se cristalizaram na commedia dell' arte. Quando o fez, e é o caso da Mandrágora, de Maquiavel, obteve excelentes resultados. Mas a obra de autores como Ariosto e Aretino, típicos comediógrafos do Cinquecento, na grande maioria dos casos tem mais a ver com literatura que com teatro. São peças que pedem antes a declamação que a representação. Nesse sentido, a Renascença na Itália, e também na França ou na Alemanha, não atinge as culminâncias do teatro inglês quinhentista, que, numa saudável irreverência para com a tradição aristotélica, mesclaria poesia e prosa, tragédia e comédia, sublime e grotesco, e partiria da força vulcânica de um Christopher Marlowe para atingir a transcendência nas maõs de um William Shakespeare.

O teatro de Leone de'Sommi, a julgar pelas informações veiculadas por J. Guinsburg em seu ensaio, padeceu dos mesmos problemas do teatro cortesão de seus colegas quinhentistas. Mas $A$ comédia do matrimônio tem outra carpintaria, mistura fábulas de sabor talmúdico à estrutura convencional da comédia ocidental, personagens tirados da tradição erudita, como namorados em dificuldades e sábios doutores, e empregados e populares trapalhões. Embora o enredo esteja situado em Sidon, no Oriente Médio, não é difícil imaginar essa cidade transformada numa metrópole portuária, próspera e barulhenta, da Itália.

As personagens compõem um minucioso quadro de costumes da vida judaica. Nos cinco atos da peça, de'Sommi entrelaça quatro tramas que caminham juntas para o desenlace. Há a história de amor de Iedidiá e sua noiva, Bruriá, separados pela morte do pai do rapaz, que legou todos os bens ao escravo Schovel, e pela cupidez de Amon e Dvorá, que pensam romper o noivado da filha para casá-la com outro, mais rico. Há a trama de Assael, filho de Efron, vizinho de Amon, e apaixonado pela irmã de Iedidiá. Um terceiro fio envolve Hemdan, advogado sem escrúpulos, que quer casar uma de suas filhas com Assael, filho de Efron. Hemdan, no entanto, acaba sendo logrado por Efron. A última situação desenvolvida pelo dramaturgo trata do escravo fanfarrão Schovel, presumido herdeiro do pai de Iedidiá e pretendente à mão de uma das filhas do chicaneiro Hemdan. Quando tudo parece perdido para Bruriá e Iedidiá, aparece o sábio Rabi Amitai, que põe ordem nas coisas. Examinando o testamento do pai de Iedidiá, descobre que tudo foi legado a Schovel, com exceção de um único bem, à escolha do filho. Iedidiá opta então por ficar com Schovel. E como os bens do escravo pertencem ao amo, o mundo volta aos eixos, e Bruriá pode enfim casar-se com seu prometido, que além do mais também a seduziu. O escravo é libertado. E tudo termina em festa.

Os fios dessa trama podem soar confusos no resumo, mas desenvolvem-se com equilíbrio e simplicidade no texto de de'Sommi. As personagens possuem uma veracidade que faz supor ter-se o autor inspirado em figuras da comunidade judaica de Mântua, no seio da qual cresceu. A ação desenvolve-se em crescente fluência, ainda que entremeada de longos monólogos explicativos. $\mathrm{O}$ cuidado com a fixação de hábitos e convenções dos judeus italianos dá ao texto um tom de comédia de costumes. A peça é dotada de uma teatralidade gritante, e merece ser posta em cena. Com alguns ajustes ao gosto moderno, que privilegia o sintético, poderia funcionar tão bem como, por exemplo, $A \mathrm{co}$ média dos erros, de William Shakespeare.

Para o estudioso de teatro, tão importante quanto a edição da Comédia do matrimônio é seu surgimento ao lado dos Quatro diálogos em matéria de representaçâo teatral. Leone de'Sommi não foi apenas um teatrólogo de gabinete. Era também produtor e diretor teatral, e chegou mesmo a pedir permissão (negada) para abrir uma casa de espetáculos. Manteve estreitas relações com a corte dos Gonzagas, onde também deve ter
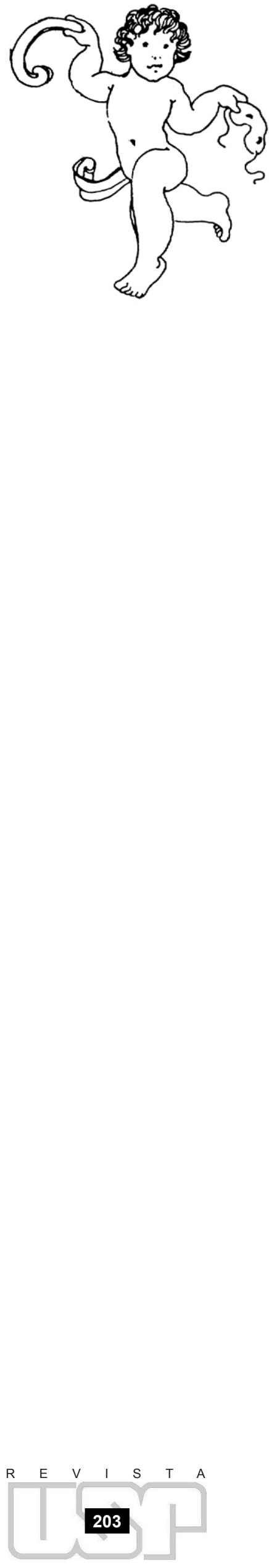
prestado serviços artísticos. Daí se compreende a extrema praticidade que vamos encontrar nos Quatro diálogos, compostos provavelmente entre 1565-66.

$\mathrm{O}$ texto foi escrito à maneira da época. Dois indivíduos abastados, talvez nobres, Massimiano e Santino, visitam o alfaiate Veridico, que é também dramaturgo, ator e diretor. $\mathrm{O}$ encontro, que deveria ter caráter comercial (Massimiano encomendou alguns trajes a Veridico), transforma-se numa conversa didática, onde os dois visitantes se colocam como aprendizes, e o alfaiate como instrutor. Um curso de teatro é o que Veridico oferece aos seus interlocutores. Nos diálogos I e II, trata da dramaturgia, sua carpintaria, formas e convenções, abarcando tragédia e comédia. No diálogo III fala de interpretação e figurinos. E no IV aborda a cenografia e o espetáculo como um todo.

A comparação do pensamento teatral de Leone de'Sommi com o de seus contemporâneos, Antonio Sebastiano Minturno (Arte poética, 1564) e Ludovico Castelvetro (Poética 1570), mostra o quanto a prática da cena favoreceu o dramaturgo judeu. Em seu escrito não há apenas uma compreensão teórica da elaboração do texto. Desenvolve-se também observação acurada sobre os modos de concretizar a peça no palco. Problemas são observados e colocados por Veridico, que também apresenta suas soluções. Num momento em que o teatro era concebido como uma maneira de expressão formal, presa a convenções de declamação, de'Sommi propõe ao intérprete uma veracidade interior que lembra o que 350 anos mais tarde será a base do trabalho de Stanislávski.

Ao mesmo tempo, de'Sommi preconiza a figura do diretor como o centralizador do espetáculo, encarregado de fazer o conjunto funcionar harmonicamente. Ora, seria preciso chegar aos Meiningers e a Antoine, no século XIX, para que o encenador fosse aceito como autor da montagem. Na realidade, embora preso às convenções quinhentistas, que em nenhum momento de'Sommi pensa negar, seu íntimo conhecimento da atividade teatral dava a sua teoria uma concretude admirável. E uma notável capacidade de intuir desenvolvimentos que somente seriam postos em livre curso alguns séculos mais tarde.

A possibilidade de o leitor brasileiro ter acesso à figura extraordinária que foi Leone de'Sommi é mais um bom serviço prestado ao nosso palco por J. Guinsburg, amigo do teatro. Não por outra razão ele ganhou recentemente o Troféu Mambembe, outorgado pela Fundação Nacional de Artes Cênicas (que o governo Collor, numa penada, acaba de desfigurar). É uma pequena mas justa homenagem a um homem que, a sua maneira, tem servido longa e fielmente o palco tupiniquim.

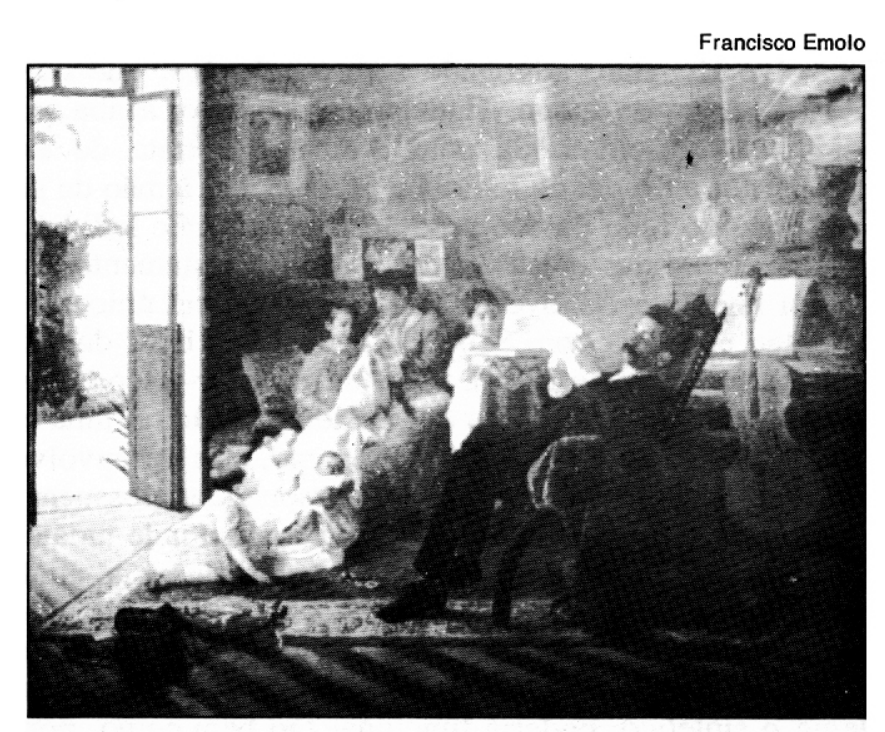

ERRATA - Na Revista USP 5, cujo dossiê é dedicado a "Cidades", no texto de Aracy Amaral ("A luz de Almeida Jr.", p. 55), faltou uma ilustração fundamental para a compreensão do artigo. Trata-se do quadro "Retrato da família Adolfo Augusto Pinto", acima. 